\title{
Construction Quality over Quantity Take Off
}

\author{
Mohd Umair $\mathrm{PhD}^{1 *}$, Tanveer Ahmad Wani ${ }^{2}$ \\ ${ }^{1}$ Department of Civil Engineering NIU, Greater Noida, UP, Uttar Pradesh, India \\ ${ }^{2}$ Associate Professor Department of Engineering NIU, Greater Noida UP, Uttar Pradesh, India
}

DOI: $10.36348 /$ sjet.2022.v07i01.002 $\quad$ | Received: 31.11 .2021 | Accepted: 03.01.2022 | Published: 15.01 .2022

* Corresponding author: Mohd Umair PhD

Department of Civil Engineering NIU, Greater Noida, UP Uttar Pradesh India

\section{Abstract}

Quality assurance and Quantity aftermaths are binary terms, which are interconnected each other closely and its ramification often chaotic in the fast pace world, specifically construction industry. Moreover, it's being used an inappropriate way as a substitute one for other. Quality over quantity, It's a simple concept, which could be understand in layman term but taught to construction organization because quality is a process per se, whereas quantity is a form of amount. However it' can be defined in one line that fits like a square peg in a round hole in today's construction/corporate environment. The reason behind that it's so inflexible to emphasize quality over quantity is simple, contemporary businesses are established merely to make money as quickly as possible and its highest possible margins. Crafting high quality components tends to be expensive and time consuming tasks, moreover it required industriousness along with proper management, which seems less attractive margin for the organization and create a question in the mind what about the profit. Lower quality work, produced quickly with a minimal time commitment per task, tends to be far more profitable, with higher margins as well as a lower cost and get more attractive price from consumers. However, corporate shouldn't entirely overlook the importance of quality over quantity. Here it's not merely a matter of profit although it's a matter of lives, which matters more than anything else. Moreover, the elements of a building structure are typically based on the kind of material used in its construction. Each and every division has space in a design takes into account the main theme or concept of the structure. Depending upon the building material(s), each element of the building is related to the other in terms of the concepts of color, dressing and outlook. The materials used for an element also, quite often, contribute to its terminology. Quality take off is widely unaccepted as one of the key factors for companies to be futile in the global market. Quality management has been a kicked issue for many years in various disciplines. The implementation of effective quality management has been witnessed and documented in the Engineering industry, which set up a paradigm for other disciplines such as the design and construction industry in the past few years, things have been changed in the construction sector by welcoming Policies that would improve construction process and lead to successful business strategies. Effective quality management, especially in (QOQ), It has been recognized as an inhibitor for performance improvement in the construction industry. On the flip side Quantity takeoffs are an important aspect of the construction cost estimating process. Quantity takeoffs are used in both large and small projects to determine actual costs ensure that a project remains profitable to the contractor, and its vital component of a final detailed estimate. General contractors, subcontractors, quantity surveyors, and estimators routinely produce quantity takeoffs during the estimation process. Whereas some in the construction industry may not routinely work on quantity takeoffs, they may still wonder what a quantity takeoff in construction is. We'll also look at the different ways qualities as well as quantity takeoffs are completed, and what are the advantages and drawbacks of these different methods. The study recommends that promoting awareness regarding the values of ethical behavior at different forum and ensuring the effective castigation for unethical activities at different stages of project life cycle might reduce the unethical practices in the construction industry. Nevertheless both terms has to be targeted as per its vitality, as we have used the word of interconnected.

Keywords: Quality, Quantity, Building, Construction Management.

Copyright $\odot 2022$ The Author(s): This is an open-access article distributed under the terms of the Creative Commons Attribution 4.0 International License (CC BY-NC 4.0) which permits unrestricted use, distribution, and reproduction in any medium for non-commercial use provided the original author and source are credited.

\section{INTRODUCTION}

The conflict of interest amongst the professionals like client and contractor project managers, site engineers, quality engineer, quantity surveyors and designers/architects play crucial roles for the unethical practices and consequently these practices have adverse impact on the construction quality as well as quantity, faith of clients and investors, confidence in the construction industry. Moreover in order to uphold green environment then we must think about quality very first. However the construction industry is a challenging and demanding business sector, that is why ethical practice in the building and construction industry is vital as same as other disciplines. As a highly debated topic, it has understood that unethical practice ranks top among the most serious ills affecting the building and construction industry. The construction industry has been facing some ethical issues that are 
comprised of but are not restricted to conflict of interest, inflation of bills, professionalism Incompetence, poor work delivery, fraud, professional misconduct, intimidation and kickbacks among several other evils. The consequences of these unethical behaviors in the industry of construction can lead to confidence reduction in the professionalism, continuous insecure practices that risk lives and property, loss of income by clients and governments, needless and baseless expenditures that raise levels of poverty and reduce the quality of life amongst other things.

Quality takeoff is defined as a state that meets the legal, aesthetic and functional requirement of a product or project by customers' requirements may be simple or complex, or they may be stated in terms of the result required or as a detailed description of what is to be done. Quality process has to be targeted and employed to ensure a certain level of quality in construction or service. It may include some necessary actions to provide for the control and verification of certain characteristics of a product or service. The basic goal of quality control is to ensure that the project, services, or processes provided meet specific requirements and are dependable, satisfactory, and fiscally sound. Essentially, quality involves the examination of a material, service, or process for certain minimum levels of quality. The goal of a quality control team is to identify products or services that do not meet a company's specified standards of quality. If a problem is identified, the job of a quality supervisor team or professional may involve discontinuing the task temporarily. Depending on the particular service or product, as well as the type of problem identified, production or implementation may not cease entirely. Quality required attention more than intention.

Although quantity takeoffs is also bit of complex. You may also hear a quantity takeoff referred to as a construction takeoff. A quantity takeoff is created to provide a list of all of the materials necessary to complete a project. The estimator is compiled a comprehensive list of costs for the associated materials. It is the way of quantifying however construction industry are busy to evolve the quantity instead quality owing to as we know that quantity comes from quality whatsoever, we are entitled to do. It has been noticed over the year the cycle of construction is being reversed direction. The construction project achievement chiefly relies on the conduct of the people taking part in the project from the early start to completion stages owing to focus barely upon quantity rather than quality. Nevertheless, there are thousands of grievances emerging every other day of different types and degree concerning operations in the industry of construction. The ethical practices within the industry as well as the critical stakeholders should be instilled and imposed. Yet, this enforcement must be founded on true and valuable comprehension on the nature, inspiration and demonstration of unethical practices if any needed results are to be assured. There exists a conflict of interest amongst the key parties such as engineer, owner and contractor. All signs show that the construction industry is required more ethical practice than any other industry because here is dealing directly with lives. Moreover, misconduct of professionals has risen and there is a huge discord between real conduct of professionals and the moral responsibilities. This study seeks to examine the ethical issues in construction. Hence, this study focuses on analyzing the unethical behaviors and suggesting the preventive measures.

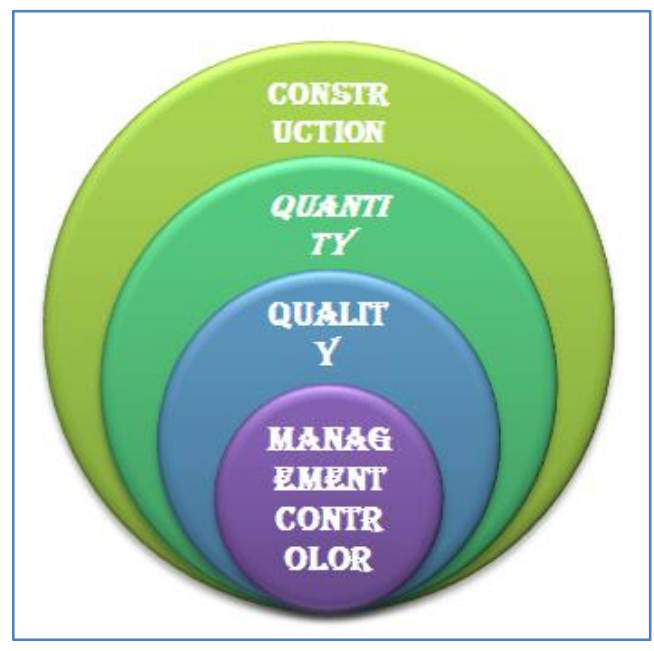

Fig-1: Process of Quality over Quantity

\section{Interconection of Quality over Quantity}

Quality is a process instead quick phase, the quality of the object is revealed in the sum of its properties. The unity of properties is, in fact, quality. As a matter of fact both terms can't be ignored at any stage. It is thanks to their properties that interact. The property is evoking one or another action.

A property of an object thus consists in its being able to produce this or that action in another object and reveal itself in its own way in this action. Moreover, the mode of its manifestation in acting on another object substantially depends on the properties or condition of the latter; a spark falling on a gunpowder store is far more dangerous than the same spark falling on damp ground, where it dies without a trace.

Every property is relative. In relation to wood and steel is hard, but it is soft in relation of diamonds. Properties may be universal or specific, essential or inessential, necessary or accidental, internal or external, natural or artificial, and so on. The concept of quality is often used in the sense of an essential property. The higher the level of organization of matter, the greater the number of qualities it possesses. Quantity is a group of homogeneous objects as a set. If it is finite it can be counted for example, a herd of 100 horses. Can be consider each horse as "one", we must ignore all the qualitative peculiarities of these animals and see them 
as something homogeneous. One and the same number "100" is the quantitative characteristic of any set of 100 objects of horse or material. Consequently, any quantity is a set if it can be counted or a dimension. However it's not right to say quantity would be first approach rather than quality.

Quantity expresses the external, formal relation of objects, their parts, properties, connections, number, dimension, set, element (unit), individual, class, degree of manifestation of this or that property.

The basis of quantitative thinking is the objective discreteness of things and processes. Quantity is expressed by number, which has two main meanings: the measure of generality of the elements when put together; the divisibility (real or putative) of an object, its properties and relations, into homogeneous elements relatively independent of its quality. For example, we form the number 5 in the process of counting, thus turning this five into a simple quantity. Five people are not simply a formal unit of five human beings; they are not something singular but a specifically divisible unity of five elements. Any number is a relatively independent, integral assembly of a certain set or a divisible unity of quantity. Moreover, quantity is not identical with number. One and the same quantity as a dimension length, for example may be expressed in different scales of measurement (meters, centimeters) and therefore in different numbers.

Besides discreteness, which serves as the real premise for the concepts of quantity and number, it is important for an understanding of the objective basis of mathematics to realize that discrete things, their properties and relations, are united in sets.

Measure for century's people has said, "Everything has its measure". The reasonable person has a sense of measure in everything: behavior, dress, eating, taste, and so on. Loss of the sense of measure, of proportion, is a bad sign and takes its revenge by putting the offender in a comic and sometimes tragic situation. Not for nothing do people dislike exaggeration, the superfluous. Measure is the quantitative limit of a given quality. Quality cannot be more or less than that limit. The whole history of philosophy from ancient times to the present day is permeated with the idea of measure. Measure is thought of as a perfect whole, a unity of quantity and quality. The concept of measure is used in various senses: as a unit of measurement, volume, as proportion of the parts to the whole, as the limit of the permissible, the legitimate, as law, as unity of quantity and quality, as their perfect wholeness, integration (a molecule of ordinary water must have two atoms of hydrogen and one of oxygen), and as a self developing system. Measure is also a certain stage in the historical development of something. Measure expresses unity of quality and quantity. For example, the atoms of various chemical elements are only distinguished from each other by the fact that their nuclei contain various quantities of protons. If we change the number of protons in the nucleus, we change that element into another. Every color has its wavelength and corresponding frequency of oscillation. Every drug has its measure: its good or bad effect depends not only on its quality but also its quantity. One and the same chemical substance in various doses may stimulate growth or inhibit it. Measure is proportion. It may embrace certain normative features: in morality knowledge of measure in everything, moderation, modesty; in aesthetics, symmetry, and proportion measure is the zone in whose limits a given quality may be modified or varied by virtue of changes in the quantity of certain inessential properties while retaining its essential ones.

\section{The transformation of quantity into quality and vice versa}

The path of development in construction, society and consciousness is not a direct line, but a zigzag. Every turn signifies the appearance of new laws that hold good for that particular leg. The limits of these laws are by no means always clearly fixed, sometimes they are conditional. Who can determine the exact limits showing where childhood ends and adolescence begins where youth begins and when it enters the quality known as "young person"?

The transition from an old to a new quality involves a leap a break in the gradualness of development. The process of development combines a unity of the continuous and the discontinuous. Continuity in the development of a system indicates relative stability, its qualitative definiteness. Discontinuity in a system's development indicates its transition to a new quality. Figuratively, one may compare this process with the action of a spring and cogwheels in a clock: the spring operates continuously, but thanks to the regulating effect of the cogwheels the energy transmitted by the spring is converted into rhythmical work. The world is not a steady stream, nor is it a stagnant pond; it is a combination of relatively stable and changing systems. Systems develop rhythmically and every stroke of the "clock of the universe" signifies the birth of the new. This is where the law of the transformation of quantity into quality and vice versa reveals itself. This law has an objective and universal character admitting no exceptions.

Quantitative changes show themselves in various ways: as changes in the number of elements of an object, the order of their connection, their spatial dimensions, their velocity, degree of development, and so on. In short, any change in quantity amounts to a change in the elements of a system. The degree of difference between an old and a new quality depends on what quantitative changes have taken place in them. For example, water is heated (increase in the speed of its 
molecules), but it remains water although it is much hotter or perhaps very hot. Only some of its properties have changed. These changes are gradual or phase a movement from one state to another. But then comes the critical boiling point. The agitated water molecules start bubbling to the surface and leave it in the form of steam. From its liquid state water passes into steam. Basically the appearance of a new property means the appearance of a new object with new laws of existence, with a new measure possessing a different quantitative definiteness. Moreover, the degree of qualitative change may differ. It may confine itself to the level of the given form of motion or it may go beyond this level. Thus measure expresses a unity of quality and quantity in relation to objects for which simple transformation is characteristic, that is to say, change within the limits of the given form of motion of matter, as in above Para in the case of the transformation of water into steam or elementary particles into each other. But measure also expresses the limits of transition from one level of a system's organization to another.

Changes in quantity and quality are interconnected; a change in quality also involves quantitative change. This is generally expressed in the fact that as the level of organization of matter raises the rate of its development accelerates. Every level of organization of matter has its specific laws of quantity. A new, better adapted construction a progeny, whose greater power of building survival guarantees wider opportunities for it to extent.

The law of the transformation of quantitative into qualitative changes and vice versa places a number of methodological demands on cognition. It allows and requires us to study an object from the standpoint of quantity as well as quality. Study of the quantitative aspect of things has enormous significance in science, technology, and everyday practice and its deep going problems in construction industry fig 2 .

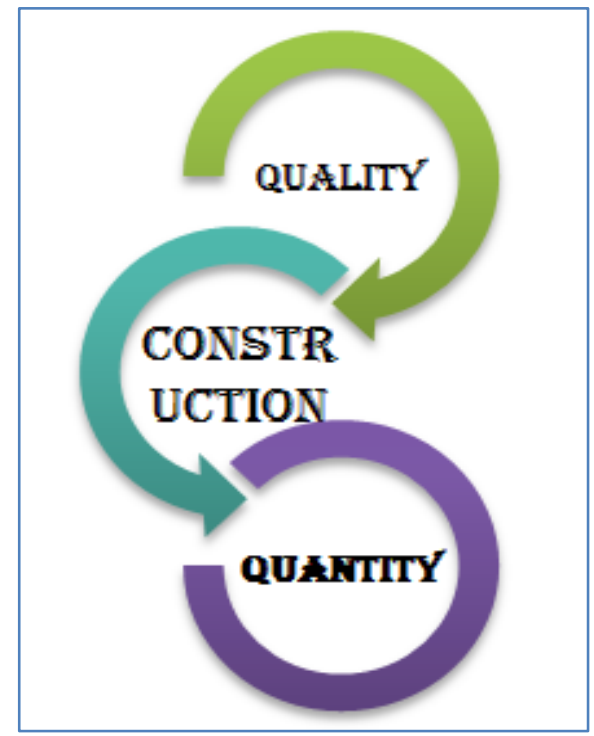

Fig-2: Transformation

\section{Quality over quantity?}

There are a number of reasons to be wise to opt quality over quantity. Here are a few of them: By choosing quality over quantity within any area of construction, you automatically open yourself up to experience the true efficiency with which you can experience meaning. Put simply, choosing quality over quantity leads you to the straightest path towards contentment and meaningfulness.

\section{Resource efficiency}

Not only you do walk the straightest path to meaning, but you also save an abundance of quantative resources that you wouldn't have otherwise if you focused on quantity over quality.

\section{These resources include the following}

A.1.Time 2.Money 3.Material-By saving these valuable resources, we can better handle our ability to direct these precious resources to things that actually matter to construction.

B. Quality Has More Depth-Whether it is the project that you are committed to do or the project that you spend time with, quality will always have more depth than quantity. This depth creates interest and as long as we're interested and engaged, we will feel good about whatever context we find project in.

C.Quality Brings Better Results-Focusing on quality rather than quantity tends to bring more fruitful results in construction industry. For example, focusing on one high quality relationship will bring us more physical and emotional benefits than focusing on mediocre relationships. Quality brings better results in a shorter time frame in most cases. If it's a habit

Below, here go through a few key areas where this concept of quality over quantity plays out practically.

\section{Critical interactions with quality \& quantity}

As with anything else, relationship is a major area of construction where quality must be chosen over quantity. Choosing a high quality relationship requires a lot of work but if this is the goal then it is absolutely worth it.Often times, people settle for mediocre relationships because they are too lazy to put the quality of work aside. Choosing the mediocre path often brings mediocre results. As a result of choosing the mediocre path, many people decided to choose quantity over quality and have many relationships that are surface level and lack substance. Moreover, individual can notice whether someone is spending time in construction with will lead to a high quality relationship or a low quality relationship. In addition, attitude of learning as well as challenge facing capability.

\section{A. Material}

Irrespective of material, every material has to be targeted an exclusive way for an instance concrete is a prime example of quality over quantity. The value of concrete in the construction as same as human spine. So it can't be ignore at any stage. Once get higher quality 
construction, one will have achieved better beneficial results in a long term because it matters a lot on lives widely.

\section{B.EXERCISE}

Engaging in high quality paper work exercise yields more results in both the short and long term than low quality paper exercise. Often times, people in construction industry spin their wheels and waste their precious resources by exercising too much on outdated methods that are inefficient. For example, light structure in construction yields better results than high loaded structure. These are domains where this powerful principle impacts our quality of construction in a major way.

\section{C.PROBLEMISTIC}

Below, here over the problems of choosing quantity over quality and how we can take advantage of this principle. The Downsides of Choosing Quantity over Quality. Here are a few of them:

Decision fatigue occurs when we have too much work available to construction. Too much work is a natural consequence of choosing quantity over quality and it really does bring about more challenges turmoil. Quantity drains your ability to make high quality and clear cut construction decisions.

\section{Cycle of Hedonism}

Choosing quantity over quality results in engaging within a cycle of hedonism that ultimately doesn't bring that contentment that we are all chasing after. The way to think like we are constantly going from point $\mathrm{A}$ to point $\mathrm{B}$ looking for the next hit of instant gratification and eventually most people that comes from quantity over quality.

\section{E. Distraction from comptitor}

Choosing quantity over quality brings about more distraction within the construction organization environment. We get taken away from our priority construction and values and aim towards more short term means instead of focusing on the long term things that matter which is quality. Distractions leave us scattered and overwhelms us.

\section{How to choose quality over quantity}

The way to choose quality over quantity is to raise your standards within all areas of construction. We have to really value ourselves if we want to do the work highest quality for the people or nation, things, habits, mindsets, so on and so forth. If we don't make the decision to value of construction then we will constantly find ourselves in a place that lacks meaning and depth. At the end of the day, this can destroy our society lives if not understand. So all of us with one thing and decide to choose quality over quantity. For example, if you have a choice between higher remuneration lacks of management or lower remuneration with management and eager to learn then chooses the lower one because these people can be managed as per organization. As you do this over time, you will begin to feel the momentum of choosing quality over quantity. There is no quick hack to choosing quality over quantity. It is simply a matter of valuing construction as well as yourself and making one high quality decision one after another.

\section{VII.CONCLUSION}

It's an age old lesson that too many of us choose to ignore. Although sacrificing the former for the latter may grant you a few short term profits, you'll quickly run out of steam when regulars fail to come back. Favoring quality over quantity will increase your company's reputation and increase construction loyalty, which will keep your construction business sustainable in the long run. However quantity would be focused in an adequate way by upholding the quality in the construction industry.

\section{ACKNOWLEDGMENTS}

I might want to express my earnest gratitude to my scholarly supervisor Dr.Tanveer Ahmad Wani for his ceaseless direction, backing and support all through the term of this venture. I need to give my genuine gratitude to our H.O.D.for their help. Last much gratitude goes to my family, companions and individual scientists. Last however not the least; I owe my cherishing because of my grandfather, for his persistent consolation and backing.

\section{REFERENCES}

1. Ho, C.M. (2011). "Ethics management for the construction industry, Engineering, construction and architectural management", 18(5); 516-537(2011).

2. Rahman, A.B.A. (2008). "Unethical conduct among professionals in the construction industry", Doctoral dissertation report, University Technology Malaysia.

3. Stewart, J., \& Hamlin, B. (1992). Competency-based Qualifications: The Case for Established Methodologies. Journal of European Industrial Training, 16(10); 9-16.

4. Succar, B. (2008). Building Information Modeling Framework: A Research Foundation for Industry Stakeholders (unpublished $\mathrm{PhD}$ report, the University of Newcastle, Australia).

5. Abu Hassim, A., Kajewski, S., \& Trigunarsyah, B. (2010). Factors contributing to ethical issues in project procurement planning: a case study in Malaysia. In Proceedings of 2010 International Conference on Construction \& Real Estate Management Volume 1 (pp. 312-317). China Architecture and Building Press.

6. Pearl, R., Bowen, P., Makanjee, N., Akintoye, A., \& Evans, K. (2005, July). Professional ethics in the South African construction industry-a pilot study. In The Queensland University of Technology Research Week International Conference (pp. 4-8). 